\title{
Erratum to: Sacral neuromodulation for faecal incontinence: is the outcome compromised in patients with high-grade internal rectal prolapse?
}

Siriluck Prapasrivorakul • Martijn P. Gosselink •

Kim J. Gorissen • Simona Fourie • Roel Hompes •

Oliver M. Jones • Chris Cunningham • Ian Lindsey

Published online: 23 December 2014

(C) Springer-Verlag Berlin Heidelberg 2014

Erratum to: Int J Colorectal Dis

DOI 10.1007/s00384-014-2078-5

The original version of this article unfortunately contains an error in the name of one of the authors. The name Martijn Gosselink should be Martijn P. Gosselink. The correct presentation of author name is presented above and in the affiliation section.

The online version of the original article can be found at http://dx.doi.org/ 10.1007/s00384-014-2078-5.

S. Prapasrivorakul • M. P. Gosselink · K. J. Gorissen · S. Fourie •

R. Hompes $\cdot$ O. M. Jones $\cdot$ C. Cunningham $\cdot$ I. Lindsey $(\triangle)$

Oxford Pelvic Floor Centre, Department of Colorectal Surgery,

Churchill Hospital, Oxford University Hospitals, Oxford OX3 7LJ,

UK

e-mail: lindseyilinz@yahoo.com 